\title{
Development of the Bioenergy as a Part of Renewable Energy in the Nordic Countries: A Comparative Analysis
}

\author{
Tapio Ranta* (D), Mika Laihanen (D), Antti Karhunen (1) \\ School of Energy Systems, Lappeenranta-Lahti University of Technology, Mikkeli, Finland \\ Email: ^tapio.ranta@lut.fi
}

How to cite this paper: Ranta, T., Laihanen, M. and Karhunen, A. (2020) Paper Development of the Bioenergy as a Part of Renewable Energy in the Nordic Countries: A Comparative Analysis. Journal of Sustainable Bioenergy Systems, 10, 92-112.

https://doi.org/10.4236/jsbs.2020.103008

Received: June 28, 2020

Accepted: September 19, 2020

Published: September 22, 2020

Copyright (c) 2020 by author(s) and Scientific Research Publishing Inc. This work is licensed under the Creative Commons Attribution International License (CC BY 4.0).

http://creativecommons.org/licenses/by/4.0/ (c) (i) Open Access

\begin{abstract}
A comparative assessment of the bioenergy and renewable energy situation in the Nordic countries, Finland, Sweden, Denmark and Norway, was conducted in this study. What factors have contributed to the current high use of renewable energy and especially bioenergy in the Nordic countries? What are the sources of renewable energy and where renewable energy is being used? The development of renewable energy use is described by time series and compared to the overall development of the EU. All of the Nordic countries have high renewable energy consumption and have already met the target for gross final energy consumption according to the Europe 2020 strategy while the EU is behind the $20 \%$ target. In total, 53.1 Mtoe renewable energy was used in the Nordic countries in 2018, which was $51 \%$ of the final energy consumption, 103.3 Mtoe. Bioenergy accounts for approximately half of renewable energy, 25.8 Mtoe, and is anticipated to develop further. Especially in Norway and Sweden the share of renewable energy was high ( $73 \%$ and 55\%) compared to Finland and Denmark $(41 \%$ and $36 \%)$. Norway is famous for hydropower ( $81 \%$ share of Renewable Energy Sources (RES) in 2018) and Denmark for wind power production (20\%), while Finland utilizes a lot of biomass for co-generation and heating (79\%), followed by Denmark (64\%) and Sweden (55\%) in 2018. At EU level, bioenergy plays even a higher role than in Nordic countries in renewable energy production (56\%) in 2017 and is anticipated to continue to grow in all end-use sectors such as heating and cooling, electricity generation and transport, in the 2020s.
\end{abstract}

\section{Keywords}

Bioenergy, Renewable Energy, Markets, Policies 


\section{Introduction}

Woody biomass, as forest residues and by-products of the forest industry, used for electricity and heat production, is the biggest source of renewable energy in the EU and will contribute significantly to the EU's target of $20 \%$ renewable energy by 2020 [1]. Sustainably harvested biomass will play a significant role in mitigating climate change and ensuring energy supply security and while promoting economic growth and employment. The National Renewable Energy Action Plans (NREAPs) indicate that around $11.8 \%$ of the EU's gross final energy consumption will originate from biomass in 2020. According to the NREAPs, bioenergy will account for $17 \%$ of the EU's predicted heating and cooling and $7 \%$ of electricity consumption. In the transport sector, bioenergy will be the dominant renewable energy source (90\%). The assessment of NREAPs also shows that total biomass primary demand will rise by $140 \%$ in 2020 , and the major part will come from solid biomass (i.e. 67\% of total biomass). However, only a few units producing advanced biofuels from wood-based raw materials has been deployed so far, despite EU risk financing tools, such as the NER 300 program [2].

According to the Impact Assessment for the 2030 Climate and Energy Framework, the use of biomass for heat and electricity is still expected to increase in the medium term as the EU aims to move towards a low-carbon economy by 2050. Several calculations have been demonstrated for the shift to a $100 \%$ renewable energy system [3] [4] [5]. EU countries have agreed on a new EU-wide renewable energy target of at least $32 \%$ of gross final energy consumption and a $40 \%$ reduction in greenhouse gas emissions compared to 1990 rates across EU [6]. The share of renewable energy sources in the transport sector was set at a minimum of $14 \%$, whereby the share of advanced biofuels and biogas by 2030 must be at least $3.5 \%$.

The role of bioenergy and forest biomass in energy production varies in the Nordic countries depending on the current energy infrastructure and support schemes for renewable energy. Differences arise from variations in natural resources and from the success of national climate and energy policies, such as feed-in tariffs, green certificates, grants, tax credits and quota systems. This also affects the role of the main bioenergy applications such as heating/cooling, electricity generation and transport fuels in each country.

The bioenergy sector in both Sweden and Finland has strong traditional know-how developed primarily within the forest industry, where wood-based by-products are typically used internally for steam and electricity production. Furthermore, district heat for local communities has been a widely used solution in both countries. Single dwellings consume, in addition to the primary heating solution, a substantial quantity of firewood for heating purposes, especially in rural regions. Expertise and know-how in bioenergy technology are large and cover the entire value chain for bioenergy, including the supply of biomass and the production of bioenergy and biofuels on a multitude of scale through various 
technologies [7]. The position of the forest industry in Norway and Denmark is rather small compared to the other Nordic countries, affecting the position of woody biomass in the energy system. In Norway and Denmark, the contribution of forestry, including the wood and pulp and paper sectors, to gross national product (GDP) was $<1 \%$ compared with $>3 \%$ in Sweden and $>4 \%$ in Finland in 2010 [8]. Its share has stayed at the same rate in Finland until today.

The aim of the study was to find out what factors have contributed to the current high use of renewable energy and especially bioenergy in the Nordic countries. What were the renewable energy sources and where renewable energy was used. The development of renewable energy use was defined in time series and compared to the overall development of the EU. Explanatory factors for the current renewable energy development were sought and future developments were assessed. The situation in the different Nordic countries was compared. In particular, the growth potential of forest-based bioenergy was assessed in relation to the use potential.

\section{Material and Methods}

\subsection{Statistical Information}

Statistical data were collected from Eurostat, the European Union's statistical office, which, thanks to the harmonized calculation techniques, allows validated comparisons between European countries. For example, the share of energy from renewable sources can be compared, which is relevant because the share of renewable energy in gross final energy consumption is one of the key indicators to be evaluated in meeting the targets set in Directive 2009/28/EC. Renewable energy consumption was also evaluated in thousands of tons of oil equivalent (ktoe) to assess similar quantities from distinct sources of energy. Renewable energy use has also been split between end-use industries, heating/cooling, transportation, and electricity generation, as there are distinct end-use subsidy systems. Different countries may also have different emphasis for different sectors. Eurostat data are also complemented by national statistics, because there are gaps in the biomass subcategories. Statistics from Eurostat cover data from 2004 to 2018

\subsection{National Renewable Energy Action Plans}

The Commission received the first Renewable Energy Action Plans in 2010. Directive 2009/28/EC laid down accounting criteria and 2020 targets for the share of renewable energy in each Member State in terms of gross final energy consumption. States were permitted to determine the renewable sources consumed separately and the promotional measures used to accomplish the goals All Nordic countries have their own energy markets and distinct biomass resources. This implies they have their own approaches to fulfill the Renewable Energy Directive commitments, including their legally binding 2020 objectives. Each nation described how they intended to do this in their domestic action plans [9] 
[10] [11] [12]. Member States subsequently submitted progress reports on the promotion and use of renewable energy every two years to track the renewable condition, the latest being the fourth report in 2018 [13] [14] [15] [16]. IEA Bioenergy Task 40 (Sustainable Biomass Markets and International Trade to Support the Biobased Economy) also supplied Country Bioenergy Progress Reports for each Nordic country $(2009,2011,2014)$, where the most recent was used in this study [17] [18] [19] [20].

According to Finland's National Renewable Energy Action Plan [9], a major part of Finland's renewable energy goal, $38 \%$, will be met through enhanced use of bioenergy and biofuels. The share of renewable energy in final energy consumption has increased ahead of target, and the minimum target of $38 \%$ was already exceeded for the first time in 2014. For forest chips, a target was set to increase their use in combined heat and power (CHP) production and separate heat production to $97 \mathrm{PJ}$ per year by 2020 . This is equivalent to 13.5 million cubic metres of wood chips. A three-part package was designed to increase the use of forest energy in order to increase the competitiveness of forest energy to the level at which the required growth could occur. The support package comprised energy support for small-sized wood, a sliding premium feed-in tariff to offset the cost difference between wood chips and alternative fuels, and a fixed feed-in tariff for small CHP plants. A producer of electricity whose energy plant is approved in the scheme will earn a production subsidy for up to twelve years in the set feed-in tariff scheme. In 2019, the use of wood chips was 8.2 million solid cubic metres [21], which implies that the initial goal will not be met by 2020 .

In Sweden, the target is to reach at least $50 \%$ renewable energy by 2020 , where the electricity certificate scheme for renewable electricity generation has been the primary tool in the electricity sector [10]. The objective is to increase electricity generation from such energy sources by 25 TWh from the 2002 level by 2020 [10]. It was introduced in 2003 and is valid until 2035, with 15 years of validity for the assigned electricity certificates. The electricity certificate scheme is a market-based aid scheme designed to increase renewable electricity generation in Sweden. The Swedish authorities have not set particular objectives for bioenergy in relation to the objectives set by EU directives. Bioenergy policies have been stable over long periods.

Norway has long experience in the development of renewable energy and almost all power generation is based on renewable energy sources. Norway is committed to a national renewable energy target of $67.5 \%$ in accordance with Directive 2009/28/EC [11]. The national target is to increase the use of bioenergy by 50 PJs by 2020, which is nearly twice the present output, is still valid but unlikely [19]. Approximately $40 \%$ of usage is wood heating in stoves, $15 \%$ is biomass in district heating, $25 \%$ is industrial biomass use (mainly in the forest industry) and $10 \%$ are biofuels as traffic fuel [19].

Because of the current regulations in the energy and transport sectors and the initiatives implemented, the share of renewable energy in Denmark is estimated at around $35 \%$ by 2020 and thus exceeds the target level of $30 \%$. Biomass con- 
tributes more than half of this renewable energy. Overall, biomass use of all types is anticipated to rise from $132 \mathrm{PJ}$ in 2012 to $166 \mathrm{PJ}$ in 2020 and is also anticipated to be the most commonly used renewable energy source in 2025 [12]. Measures to encourage the use of renewable energy in the EU-including support schemes-are national and, like other EU nations, Denmark has established its own domestic support scheme, which involves subsidies, political arrangements to establish wind farms, tax exemptions, a biomass agreement and support for information and research campaigns. Since the Biomass Agreement of 2000, a premium feed-in tariff for renewable electricity has been in use in Denmark but has since been amended several times. The premium tariff for renewable electricity installations has been awarded through tenders. Support has now been extended to all renewable energy sources and is collected by electricity users through the public service obligation (PSO) tariff. Biomass being a non-taxable fuel, favors its use in district heating generation. However, there are also regulations that ensure that a large proportion of district heat generation is based on co-generation. Taxable fuels for non-taxable fuels, i.e. biomass, cannot be exchanged with separate heat generation. Therefore, expansion of electricity production with biomass can only occur if biomass is used in cogenerated heat.

\subsection{Incentives for Biomass-Based Renewable Energy}

The general energy policy of all EU countries has supported biomass for energy over the last decade, although the policies have changed over the years. Research and development has been continuously supported, and range of subsidy schemes have been implemented, particularly for combined heat and power (CHP). Fossil fuel taxation has been the most efficient policy tools, although it directed on the fuels used in heat and transportation markets. Together with a tax regulation such as tax exemption for biofuels, the primary support scheme for transport is a quota system. Typically, renewable energy investments are supported by state subsidies.

Sweden and Norway launched an electricity certification system with the aim of significantly increasing the production of renewable electricity. Renewable electricity generating plant owners who fulfill the Electricity Certificate Act criteria may sell one certificate per MWh generated. The common goal is to create 26.4 TWh of new renewable electricity generation by 2020 [14]. Later, the target for the common market with Norway increased from 26.4 TWh to 28.4 TWh of new, renewable electricity production by 2020 [14]. Norway is committed to the financing of $50 \%$ of the certificates regardless of where the production is located in both countries. Demand for electricity certificates is created because all electricity suppliers and some electricity consumers are obliged to purchase electricity certificates equivalent to a certain percentage (quota) of their electricity sales/consumption. The production of green electricity is expected to increase by 2 TWh each year until 2035. Generally, the support period ends 15 years after initiation [14]. One certificate is granted for each MWh of electricity. This scheme stimulates the expansion of renewable electricity production as, in rela- 
tion to their revenue from electricity sales, renewable electricity producers receive an additional source of revenue. Since biomass is used only in cogeneration in electricity generation (there are no condensing plants for biomass in Sweden and Norway), this has also contributed to district heat production.

Finland relies on a sliding premium subsidy system targeted for CHP plants, which ensures forest energy competitiveness in relation to peat regardless of the emission allowance cost. The fixed feed-in tariff for small CHP plants has been less popular. The primary reason has been the low price of electricity and the low importance of electricity in the overall economy, which has not encouraged investments. Energy subsidies for small-sized wood have been compensation for the high harvesting cost of young forest stands and first thinning sites. This has probably resulted in small-sized wood, i.e. pruned small-diameter stems and unpruned small-sized trees, becoming the main source of forest chips, half of the total volume in 2019 [21]. Finnish financial incentives for the use of biomass in energy production are generally quite modest compared to some other EU countries, which apply significantly greater financial measures [22]. One reason for this might be that all Renewable Energy Source (RES) subsidies are financed from the state budget, i.e. electricity consumers are not charged directly to finance RES support in Finland. Compared to the EU average level, other Nordic countries have also been cost-effective [22].

\subsection{Fuel Taxation}

Fossil fuels are taxed in heat production. The excise duties for fossil fuels include both energy content and carbon content tax in all Nordic countries. Sweden, Denmark and Norway also have a tax on sulfur based on the fuel's sulfur content. Imported fossil fuels like coal in Finland have a strategic stockpile fee. The carbon content tax rates have been significantly increased over the years. Coal is an imported commodity with an almost identical price level across the Nordic region (2.4 - $3.7 € / G J$ in 2019), whereas each country has its own excise tax level. EU legislation has set a harmonised minimum excise duty rate of $0.3 € / G J$ for coal used for non-business use as a heating fuel. In all Nordic EU-member countries, the tax is clearly above the minimum. In Sweden, the tax level is the highest in the Nordic countries. Norway does not use peat in energy production and coal only at one plant, and it is not subject to the carbon tax.

\subsection{Biomass Resources}

Forest-based bioenergy is the most important source of renewable energy in Finland, accounting for about $80 \%$ of the renewable energy used. The most important reason for the success of biomass fuels has been the positive development of the forest industry. The forest industry is the largest producer of wood fuels, but the industry is also the most significant user of wood fuels. Almost two thirds of the use of wood fuels occurs in the forest industry. The total annual biomass production in Swedish forests is estimated to be about 76 Modt (Megaton oven dry substance), which corresponds to approximately 1.36 EJ. More 
than half of that quantity is left at the forest site, due to market constraints and technical, financial, environmental etc. restrictions [18]. However, for more than a century, the growth of Swedish forests has exceeded fellings and losses. Recent inventory data obviously demonstrate that in the future the gap will increase. This is due in part to the anticipated rate of demand in the pulp and paper industry, but the primary reason is forest growth acceleration. It is projected that the annual surplus will be 50 million $\mathrm{m}^{3}$ in addition to the current situation [18].

Forest resources have the most significant potential for increasing bioenergy production in Norway. It is estimated that the potential for increased biomass supply with the present volume of logging will be 20 - 25 PJ, of which logging residuals account for the major part. Availability of biomass is not considered to be a limiting factor for the growing use of bioenergy in Norway. However, in the short term, an increased supply of biomass would require higher prices to make producers motivated to supply biomass. For this reason, the cost of purchasing biomass compared to other energy sources is a major challenge [19].

Bioenergy production in Denmark has steadily increased since 1990. In Denmark, the use of biomass in energy production is common in both the private and public sectors, but biomass is a limited resource. Since Denmark is a small country, it is possible to regulate with either a fuel-based scheme with large biomass import or an electricity-based scheme where biomass usage is planned based on domestic reserves [20].

All the Nordic countries have felled less wood than the potential fellings, but at the same time they have imported of round wood except Norway (Table 1). Potential fellings were defined according to the EFISCEN model [23]. National estimates for sustainable felling levels may have increased after earlier national forest inventories. For example, for Finland and Sweden the growing stock and annual increment and potential fellings were updated according to the latest inventory values in 2018 [24] [25]. Finland and Sweden can increase fellings, which could also provide more biomass for energy use (by-products and forest biomass), whereas in Denmark and Norway the volume-based increase is limited. Overall, the growth of Nordic forests is expected to increase, as a result of improved forest management practices (fertilization, seedling management) and climate change (longer growing season).

Table 1. Growing stock (2015), annual increment (2010), annual (2017) and potential fellings (2015), net import (2015), million $\mathrm{m}^{3}$, Swedish and Finnish values were updated to 2018 [23] [24] [25].

\begin{tabular}{cccccc}
\hline & $\begin{array}{c}\text { Growing } \\
\text { stock }\end{array}$ & $\begin{array}{c}\text { Annual } \\
\text { increment }\end{array}$ & $\begin{array}{c}\text { Annual } \\
\text { fellings }\end{array}$ & $\begin{array}{c}\text { Potential } \\
\text { fellings }\end{array}$ & $\begin{array}{c}\text { Net } \\
\text { import }\end{array}$ \\
\hline Sweden & 3549 & 119 & 90 & 94 & 8 \\
Finland & 2473 & 107 & 63 & 84 & 9 \\
Denmark & 126 & 6 & 3 & 3 & 1 \\
Norway & 1165 & 26 & 12 & 14 & 0.2 \\
\hline
\end{tabular}


According to the Finnish experience, the techno-economical forest biomass potential for energy use is, on average, one fourth of the felling level [26]. This is a rough indicative estimate, but tells the magnitude of the potentials. The techno-economic potential refers to the delineation of how much it makes economic sense to harvest residues. In other words, areas with low yields and areas far from places of end-use are delimited. It complies the REDII sustainability criteria. The sustainability of Nordic biomass production is regulated through a range of national policies and legislation and covered by EU regulation through, for example, RED II. The ecological constraint applies in particular to stumps for which the potential without them also has been determined. Stumps represent a third of the potential, the rest consist of logging residues and small-sized energy wood. Forest owners' willingness to sell energy wood is not estimated here, but particularly stumps have the lowest market accessibility [27]. Sustainability criteria may also limit stump use in the future. In Sweden harvesting is mainly targeted at logging residues, whereas small-sized energy wood is the main fraction in Finland. The techno-economical potentials were estimated according to the annual and potential fellings listed in Table 1 using the coefficient of Finnish experiences. Norway's current use was estimated from total woody biomass use (share of forest fuels 10\%). Firewood was not included in the current use, which has been the main use in Norway. Especially in Finland the potential fellings were closer to reality, since fellings will increase in the future due to forest industry investments. In Sweden, forest fuel use can double and in Finland one and half fold in accordance with domestic resources, whereas current use in Denmark is mostly based on import and domestic supply is very limited. In Finland, stump biomass is relevant in order to achieve the target level of 97 PJ. Norway has a lot of domestic potential, but the demand is low (Table 2). In Finland, the use of forest chips remained almost unchanged until 2019 (preliminary estimate 58.9 PJ).

\section{Results and Discussion}

\subsection{RES in the Nordic Countries}

All Nordic countries have already achieved and exceeded the defined RES 2020 target, while EU lag behind the $20 \%$ target. For Sweden, where about one-fourth of renewables consists of hydropower, the target set is the EU Member States' highest: nearly half (49\%) of its gross final energy consumption should be covered by renewable energy. For Finland, this share is 38\% and for Denmark 30\%. In Norway the national target for renewable energy is two-thirds (67.5\%). Norway is famous for hydropower (81\% share of RES in 2018) and Denmark for wind power production (20\%), whereas Finland uses a lot of biomass for co-generation and heating (79\%), followed by Denmark (64\%) and Sweden (55\%) in 2018 (Figure 1). Also, at EU level, bioenergy has been the largest source of renewable energy, $56 \%$ in 2018 . The share of renewables in gross final consumption has steadily increased in all Nordic countries during the last dec- 
ade but increased fastest in Denmark and Sweden, (21\% and 16\%-unit) (Figure 2). This increase is based mainly on wind energy at both countries. At EU level, the rate of growth has been slower (9\%), especially due to slower growth in large economies (Germany, UK, and France).

Table 2. Forest fuel use and potential (PJ) case I = stumps included, case II = stumps excluded (National Statistics).

\begin{tabular}{cccccc}
\hline & $\begin{array}{c}\text { Forest chips } \\
\text { use in 2015 }\end{array}$ & $\begin{array}{c}\text { Annual } \\
\text { fellings I }\end{array}$ & $\begin{array}{c}\text { Potential } \\
\text { fellings I }\end{array}$ & $\begin{array}{c}\text { Annual } \\
\text { fellings II }\end{array}$ & $\begin{array}{c}\text { Potential } \\
\text { fellings II }\end{array}$ \\
\hline Sweden & 55.1 & 162.0 & 169.2 & 108.0 & 112.8 \\
Finland & 57.7 & 113.4 & 151.2 & 75.6 & 100.8 \\
Denmark & 13.3 & 5.4 & 5.4 & 3.6 & 3.6 \\
Norway & 4.1 & 21.6 & 25.2 & 14.4 & 16.8 \\
\hline
\end{tabular}

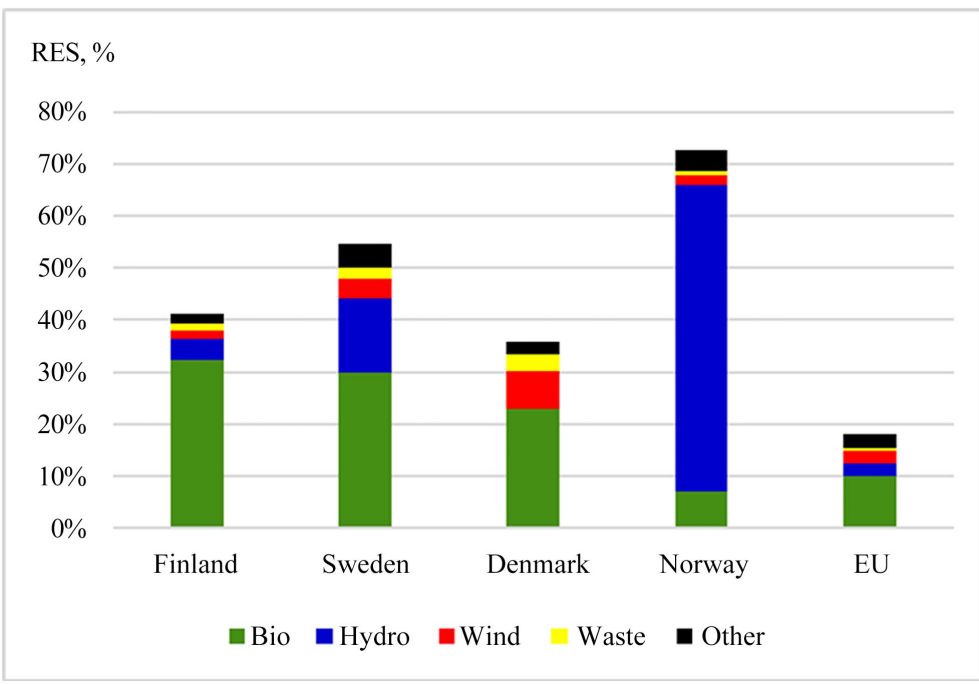

Figure 1. Share of renewables in gross final energy consumption in 2018 (Eurostat).

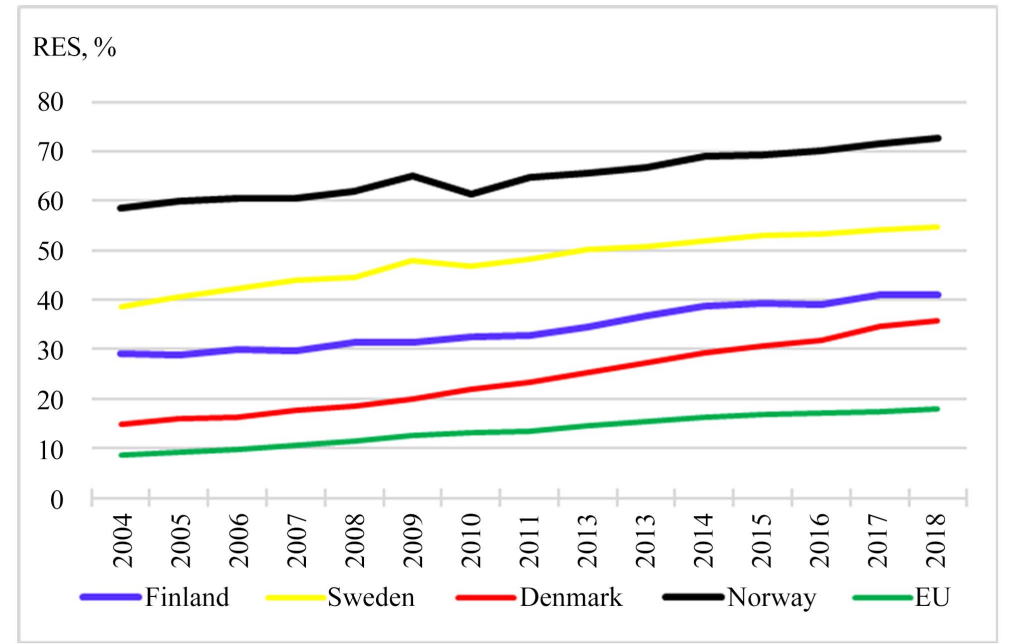

Figure 2. Share of renewable energy in gross final energy consumption (2004-2018) (Eurostat). 
Primary production of renewable energy by type is presented in Table 3, where Sweden has the highest volumes of renewables measured as thousand tonnes of oil equivalent (toe). Bioenergy consists of solid biofiuels, biogas and liquid biofuels, of which the share of solid biofuels varies from $69 \%$ to $94 \%$ depending on the country. Solid biofuels include charcoal, fuelwood, wood residues and by-products, black liquor, bagasse, animal waste, other vegetal materials and residuals and renewable fraction of industrial waste, but not fuel peat. Waste consists of the renewable part of municipal waste, which has the highest share, 9\%, in Denmark. Other column consists of solar (thermal and photovoltaic) and geothermal, with the highest share in Sweden, $8 \%$. The Nordic countries account for $22 \%$ of the total amount of renewable energy in the EU. This is due in particular to a significant share of hydropower, $61 \%$ across the EU, bioenergy accounts for $19 \%$, waste $18 \%$, wind $11 \%$ and others $10 \%$.

The origin of solid biomass is mainly forest industry by-products and forest biomass. Agricultural biomass is only an important source in Denmark (Table 4). Biomass is mainly sourced domestically except Denmark, which imports pellets and forest chips. Waste is not included in Table 4, but Sweden imports one fourth of the waste used for electricity production. The import percentage values were calculated from the average values for the years 2013-14. In Finland and Sweden, the domestic forest industry produces a lot of by-products for energy use. Finland also imports pulpwood from Russia, where part of the imported volume ends up as energy (black liquor, bark, sawdust). However, imports have more than halved from the level during 2000-2008. The share of imported forest chips has also decreased during recent years and was 6\% in 2015.

Table 3. Primary production of renewable energy, 1000 toe, 2018 (Eurostat).

\begin{tabular}{ccccccc}
\hline & Hydro & Bio & Wind & Waste & Other & Total \\
\hline Finland & 1144 & 9490 & 502 & 349 & 579 & 12,064 \\
Sweden & 5349 & 11,182 & 1429 & 817 & 1678 & 20,455 \\
Denmark & 1 & 3793 & 1195 & 505 & 402 & 5897 \\
Norway & 11,934 & 1380 & 333 & 208 & 791 & 14,647 \\
EU & 30,081 & 134,845 & 32,453 & 10,420 & 34,356 & 242,155 \\
\hline
\end{tabular}

Table 4. Solid biomass sources (\%) in energy production and share of domestic and imported sources [10] [11] [12] [13]. Forest bio $=$ Forest residues, Indust.bio $=$ Forest industry by-products, Agribio $=$ Agricultural biomass, Domestic $=$ Domestically sourced biomass, Imported = Biomass sourced from abroad.

\begin{tabular}{cccccc}
\hline & Forest bio & Indust. Bio & Agribio & Domestic & Imported \\
\hline Finland & 35 & 65 & 0 & 86 & 14 \\
Sweden & 29 & 70 & 1 & 94 & 6 \\
Denmark & 49 & 17 & 34 & 47 & 53 \\
Norway & 63 & 17 & 0 & 95 & 5 \\
\hline
\end{tabular}


The development of solid biofuel use has increased during the first half of the last decade in Sweden, and an on the last decade in Denmark and Finland (Figure 3). The growing trend is expected to continue, as bioenergy still plays a major role as a substitute for fossil fuels in combined electricity and heat production in all other Nordic countries except Norway. The downward trend in Norway is due to closures in the pulp and paper industry and a decrease in the use of firewood used during mild winters for heating in private homes.

Non-renewable solid fuel use has decreased during the last decade especially in Denmark (61\%) and Finland (44\%). In Finland, fluctuating rates of hard coal and energy peat use in electricity production have caused the variation, and their use has decreased especially in recent years despite the upturn in 2013 and 2016 (Figure 4). The increase in the use of fossils was due to lower prices for coal and lower availability of domestic fuels in those years. Non-renewable solid fuels consist of hard coal and derivatives and fuel peat, but non-renewable waste is not included.

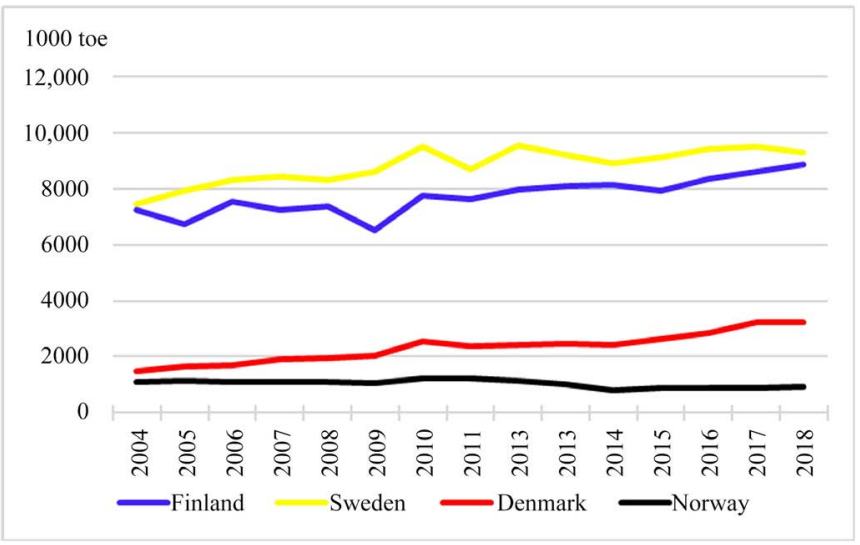

Figure 3. Total energy supply of solid biofuels, (2004-2018), 1000 toe (Eurostat).

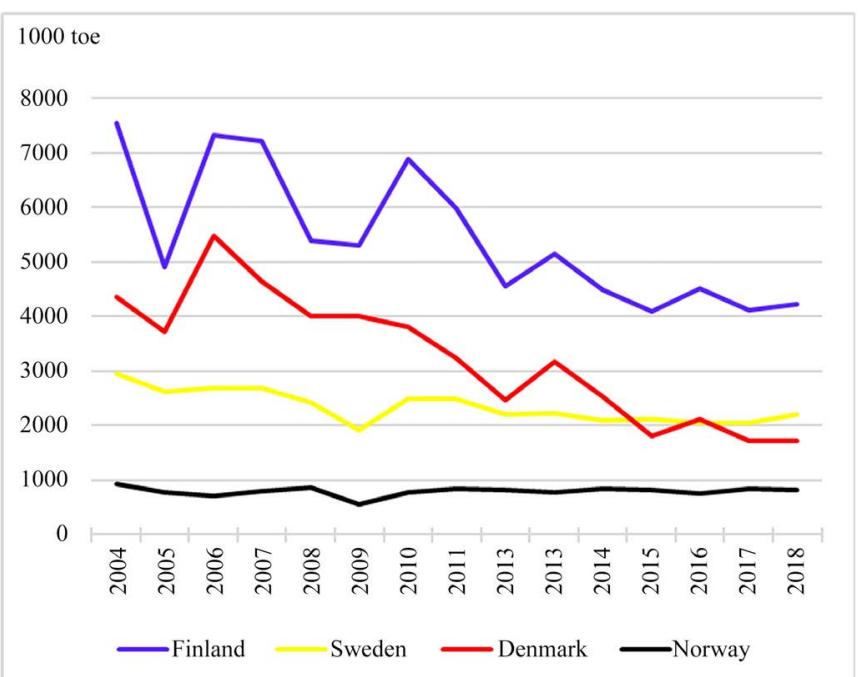

Figure 4. Total energy supply of solid fossil fuels and peat fuels (2004-2018), 1000 toe (Eurostat). 
In Finland and Sweden, solid biofuels dominate (65\%, 71\%), whereas in Denmark and Norway they were used almost at the same level as non-renewable solid fuels in 2018 (Figure 5). Peat is still a fuel in the energy system in Finland despite its decreasing use. The use of non-renewable solid fuels will define the potential capacity for future use of solid biofuels, since the existing boiler capacity is the primary target for fuel replacement or boiler retrofits. Fluidised boiler technology offers the fastest possibility for fuel replacement, whereas pulverised coal technology enables only a small share (5\% - 10\%) of pellet use with coal and requires retrofits for a higher share of pellets or for forest chips (biomass burners, gasifiers and biomass feeding systems). Biocoal could offer higher biomass shares, but the biocoal market is currently immature.

Non-renewable solid fuel (coal and peat) use was 9.0 Mtoe in the Nordic countries in 2018. Finland will be the main market for wood fuels with 4.2 Mtoe non-renewable solid fuel use, followed by Sweden at 2.2 Mtoe and Denmark at 1.7 Mtoe in 2018 (Figure 5). Finland and Denmark are part of the Global Alliance to Power Past Coal, where the aim is phase out coal in the energy system before 2030. Sweden has the even more ambitious target to be coal free by 2022 . Norway has no specific target, but only one plant using coal. According to the Finnish energy and climate strategy, coal use should be totally ended, and fuel peat use halved by 2029. During the last decade, annual use of coal has varied from 1.5 to 3.5 Mtoe and fuel peat from 1.4 to 2.5 Mtoe.

As a summary the share of renewable energy in gross final energy consumption has steadily increased in all Nordic countries. The growth of renewables has been based especially on bioenergy. Forest fuels allow for 1.7 - 2.5 Mtoe (20 - 30 PJ) additional growth according to previous Table 2. This accounts $19 \%-28 \%$ of the non-renewable solid fuel market. Increasing felling and round wood imports may increase the amount of by-products to some extent. Similarly, it is possible to increase the use of agricultural biomasses, but their amounts have not been estimated in this study. Agricultural biomasses suitable as energy sources consist of energy crops, straw, husk, grasses, and manure. They are most relevant in Denmark, which also has significant imports of pellets (Table 3). In practice, most fossil non-renewable solid fuels need to be replaced by other forms of energy production such as renewable (wind), or carbon free (heat pumps, nuclear) electricity generation or energy savings. Finland is increasing its nuclear energy production, while Sweden is reducing its share of electricity production. Based on the developments in Nordic countries, in the future there will be less cogeneration and more separate production of electricity and heat.

\subsection{District Heating}

Despite the considerable variation in district heating production systems within the Nordic countries, there are also some similarities. The local availability of different energy sources and the energy infrastructure dictates the selection of energy sources. Particularly biomass and municipal biowaste are typical sources of renewable heat energy in all Nordic countries. The important role of these 


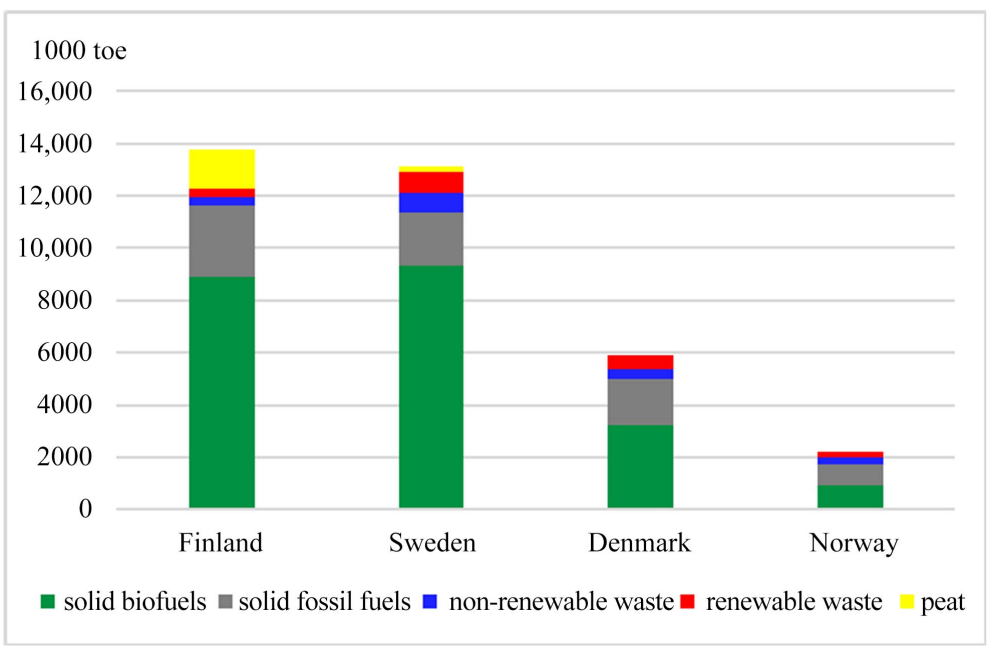

Figure 5. Gross inland energy consumption by renewable and non-renewable solid fuels (2018), 1000 toe (Eurostat).

energy sources is not solely due to the resources available but can also be partly explained by policy measures. In Finland, woody biomass is often used as a co-fuel together with peat in district heating plants. Coal is rarely used together with biomass or co-fired with small shares of wood pellet fuels in CHP plants. Biomass co-combustion with different wood fuel sortiment is also quite common. Co-combustion of coal depends on a tax scheme that taxes heat generation fuels and taxes electricity only when consumed.

The share of biomass in heat production has increased especially in Denmark, although the highest share remains in Sweden (Figure 6). However, the share of fossil fuels is still quite high in Denmark and Finland, whereas biomass and an increasing proportion of waste incineration dominate the production of district heating in Sweden. One reason for this is that household waste imports have increased. Importing household waste is comparatively inexpensive, and in latest years Sweden has extended its ability for waste incineration [14]. Norwegian district heating is heavily based on waste incineration plants (50\%). Another significant source of heat is electric boilers and heat pumps, which accounted $29 \%$ in heat production in 2017 [15]. The low price of electricity in relation to the investment costs for bioenergy systems is the main barrier to increased use of bioenergy in Norway. District heating prices in Norway are related to electricity prices (electricity taxes and network tariffs). The role of heat pumps in other Nordic countries was lower, in Finland and Denmark 6\%, in Sweden 14\% in 2017 [13] [14] [15] [16]. However, the share of heat pumps in heat production has risen in recent years. The remainder of the renewable heat production is made of biomass and derived heat.

Most of the heat comes from cogeneration. In Denmark 75\% and in Finland $70 \%$ of all district heating comes from co-generation, which is the EU's largest share. The high efficiency of co-generation is anticipated to be one of the most important success factors in district heating. In Sweden, the share is much lower at $40 \%$. National policies have had a significant effect on growth, as stated above, 


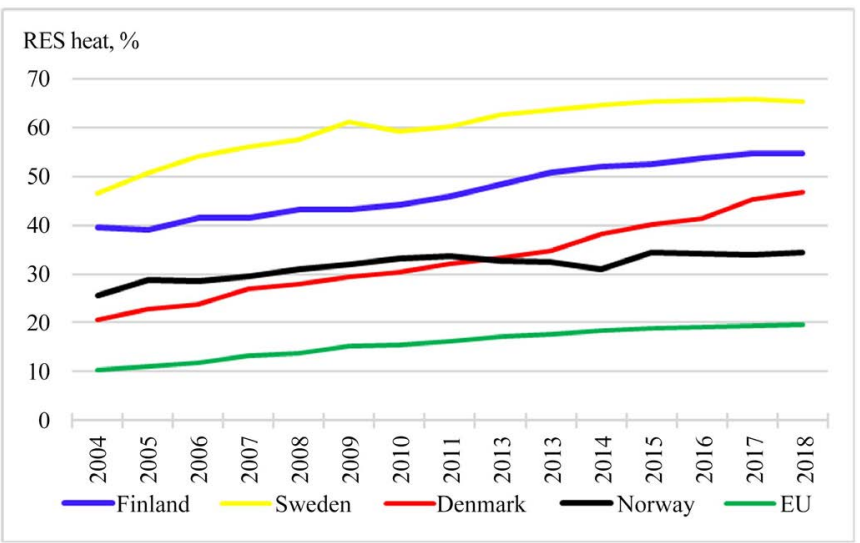

Figure 6. Share of renewable energy in heating and cooling (2004-2018) (Eurostat).

and can explain the distinctions between countries. Due to high carbon dioxide taxes on fossil fuels in relation to other policy initiatives, growth has been greatest in Sweden in the early 2000s. In Finland, development has been slower, because the lower price difference between biomass fuels and competing fossil fuels. Due to the important role of natural gas and coal as heating fuels, the evolution of the share of renewable energy has been moderate at EU level.

The large shares of district heating in the Nordic countries are the result of substantially different regulatory regimes. Denmark and Norway have relied on detailed regulation. For example, the municipal energy planning indicates certain areas for district heating and other areas for natural gas heating in Denmark, which makes collective energy distribution systems mandatory. In Norway, plants with a thermal load of more than 10 megawatts have a mandatory obligation to provide district heating. If there is a district heating system in the region, municipalities can decide on mandatory access to the district heating system for new buildings. Grid operators are required without discrimination to connect new bioenergy heating plants to their grids. However, the proportion of biomass energy use has declined in Norway because of a declining trend in the pulp and paper industry. The main share consists of residential firewood used for heating, and a smaller share comprises forest chips used in district heating or organic household waste combusted in incineration plants.

As a summary, in the Nordic countries, district heating plays a significant role in municipalities due to existing infrastructure (district heating pipelines and circulating water heating at homes). Biomass is the most important fuel as a substitute for fossil fuels, but heat pumps have also become more common for individual heating and in the district heating sector, which means the electrification of heating. In industry, the importance of biomass is even greater, especially due to the significant role of the forest industry in Sweden and Finland.

\subsection{Electricity Generation}

The share of renewable energy in electricity is highest in Norway, who produces hydropower for export (Figure 7). Other renewables category include electricity 
generation from gaseous and liquid biofuels, renewable municipal waste, geothermal, and tide, wave and ocean power. Denmark produces the most wind electricity, $69 \%$ of all renewable electricity, and this has clearly increased during the last decade (Figure 8). Finland is famous for biomass-based CHP, where its share was $36 \%$ of renewable electricity in 2018 . However, its use has risen very modestly over the past decade (Figure 8). Peat is typically co-fired with wood fuels in Finland, which is expected to be replaced by biomass over the next decade. At the moment no biomass or fossil solid fuels are used in condensing plants. Coal-fired condensing plants are mainly oriented towards supply security reserve. In Finland, the share of renewable energy is affected by a large share of nuclear energy, 25\%, and a large share of imported electricity, 23\% in 2018. The share of nuclear power continues to rise (over 40\%) when new nuclear power plants have been commissioned. Nuclear power replaces imported electricity and fossil energy sources. In Sweden, the share of nuclear power is even higher than in Finland, $41 \%$ in 2018. In Sweden, however, the share of nuclear power will decrease in the future. In the EU, wind is the most significant sources of renewable electricity (36\%) following by hydro (33\%). Also, the proportion of solar power is higher than in the Nordic countries.

The Swedish district heating system is poorly utilised in CHP production. After the reform of the electricity market, the originally low electricity prices have not contributed to expansion and the capacity utilisation rate has decreased in recent years. However, as electricity prices rise and trade in green electricity certificates increases, there may be high demand for biomass in CHP production. The ongoing horizontal and vertical integration of energy companies in Sweden also shows that the combined heat and power production may become more important in future electricity generation [7]. CHP is much more widely used in Finland, where the challenge is rather to increase the share of wood fuels in district heating systems. The existing pulverised coal CHP plants, where the potential biomass use is limited, are the main reason for this. Also, older fluidized bed boilers require peat mixed with biomass to work properly.

The system price of the Nordic electricity exchange derived from the sell and buy bids on the exchange in Nord Pool. Long-term electricity future prices, exchanged in Nasdaq OMX, vary between 22 - $27 € /$ MWh (2021-2021), i.e. a decreasing trend from the current price level. Successful savings programs, expanding wind power and improving nuclear power effectiveness have resulted in "excess supply" of electricity and a very low basic price. In practice, Nordic water reserves are the main determining variable for spot price. However, due to electricity transmission restrictions, area prices have occasionally been higher than the system price, as has been the case in Finland. Typically, peak prices occur during the cold winter season with its high electricity demand. Another challenging situation in all the countries is that heat production is subject to fuel taxes, while electricity production is subject to consumption taxes. Thus, carbon dioxide taxes are not levied on fuels in power generation, which reduces the competitiveness of renewable fuels compared to fossil fuels. 


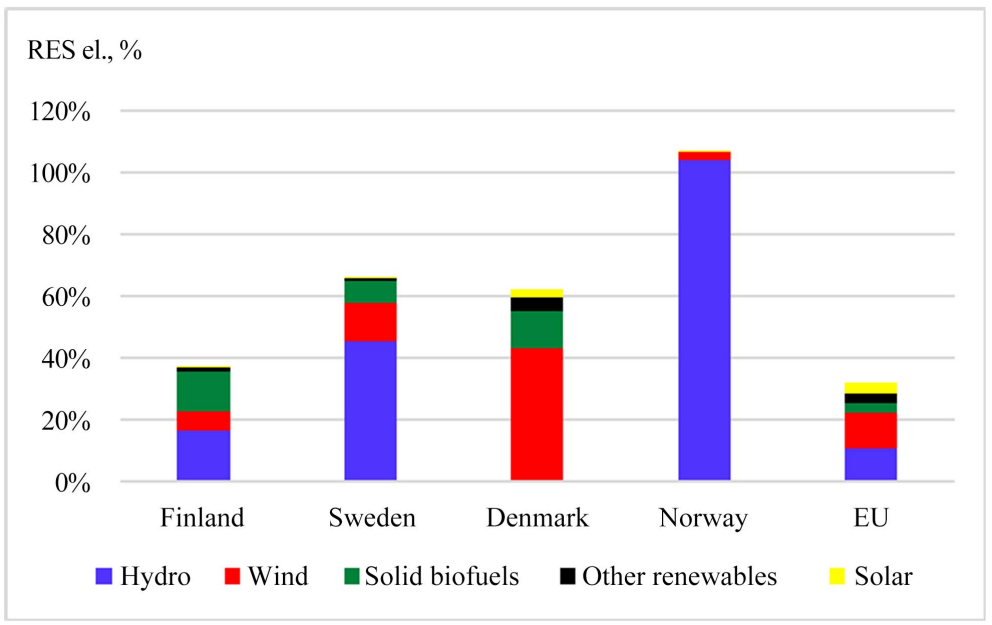

Figure 7. Share of electricity from renewable sources in 2018 (Eurostat).

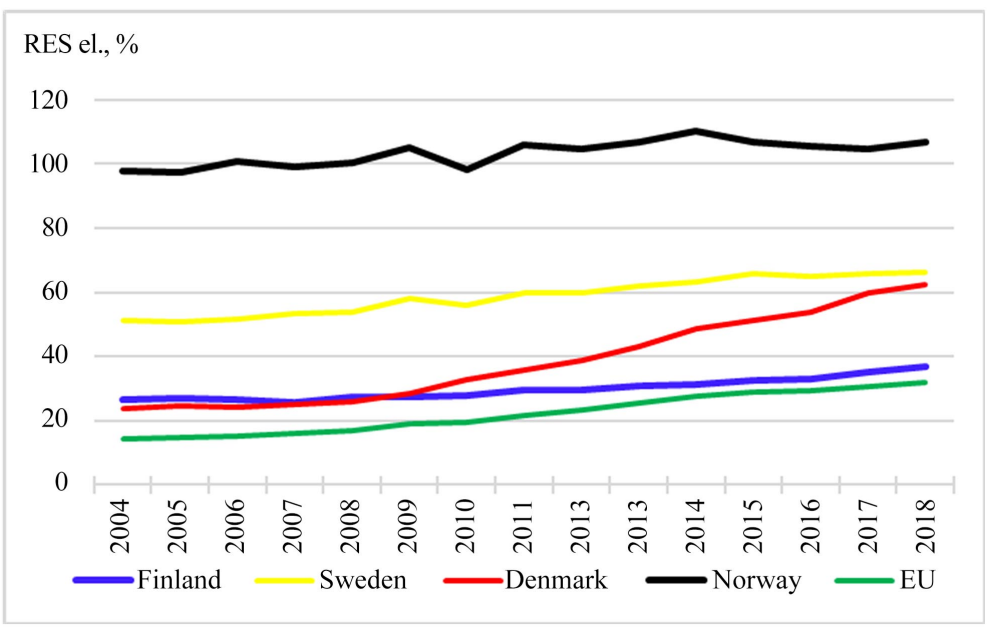

Figure 8. Share of renewable energy in electricity (2004-2018) (Eurostat).

The Finnish energy and climate strategy also estimates that CHP will stay roughly on the same level as today up to the year 2030. However, $3150 \mathrm{MW}$ of CHP electricity production capacity is to be decommissioned before 2030, 1240 MW of which is based on biomass [28]. The current market situation (low electricity prices) does not encourage CHP investments without specific incentives. The economics of CHP is under pressure in Finland, but also Denmark and Sweden, with a trend towards heat-only boilers [29]. The tightening of the taxation of fossil fuels and the increase in the price of emission allowances have an impact on the willingness to fuel switch to biomass, but do not improve the competitiveness of plants in comparison to other types of energy production. New wind power investments are made without subsidies, but the challenge is the variability of production and bioenergy is on the other hand primarily a solution for heat production. However, bioenergy can be used to provide flexible resources for both energy supply and energy storage. Bioenergy RES hybrids provide the opportunity to optimally switch between distinct sources of energy [30]. 
As a summary, the role of biomass in electricity production is rather modest and based solely on CHP production. Based on Finnish experiences, the increasing use of biomass in CHP production requires an increase in the price of electricity and emission allowances in order to maintain profitable CHP production. In the other Nordic countries, the most significant growth assumption for renewable electricity generation is based on wind energy, with the exception of Norway, which generates its electricity from hydropower.

\subsection{Transportation}

Sweden has a high share of renewable energy in the fuel consumption of transport, 30\%, followed by Norway (20\%), Finland (15\%) and Denmark (7\%) in 2018 (Figure 9). In all other countries except Finland, the share has increased throughout the period under review. The fluctuation of the Finnish share is due to the possibility of transferring the surplus to the next year. Advanced biofuels' double-digit shares have helped Finland and Sweden to go beyond the goal, while electricity use in cars is prevalent in Norway. These are the only countries in EU that have exceeded the $10 \%$ target for 2020 set by renewable energy directive (2009/28/EC) [31]. The target set by Finland itself is $20 \%$ by 2020 and by $203030 \%$ without double counting. Limiting emissions from traffic is one of the most important ways to reduce emissions in the effort sharing sector in Finland. The EU's target for renewable energy in transport will be $14 \%$ by 2030 , including at least $3.5 \%$ of advanced biofuels that will also be double counted towards the $14 \%$ target. Most of the targets are pursued with biofuels, but when used in road transport, renewable electricity is also included and calculated four times its energy content to the $14 \%$ renewable energy target. Norway is a global leader in electric cars, and in 2019, electric cars accounted for 56\% of new cars sold. The reasons for this development have been exemptions from Norway's high registration taxes, VAT and road tolls.

However, biofuels in transportation are expected to be the next growing market for forest biomass, since it is a suitable raw material for advanced biofuels. They are the primary fuel option for heavy traffic and long-distance transport such as marine freight and aviation. Also, private cars use mostly advanced biofuels mixed into gasoline and diesel (drop-in fuels) but also through alternative renewable fuels such as ethanol (E85) or biogas. For example, in Finland the target for biofuel capacity is 1.1 Mtoe by 2030, when the increase will be 600 ktoe from the existing level. To meet this need, the forest biomass would be $0.5-0.7$ Mtoe per year.

As a summary, based on the current development, all the Nordic countries, with the exception of Denmark, will easily reach the EU's 2030 target for renewable energy in transport and aim for higher shares than at present. Sweden and Finland base their targets on advanced biofuels and Norway on the electrification of transport. This means that in the next decade, limited bioenergy resources will be diverted from other energy production to the production of advanced transport biofuels. 


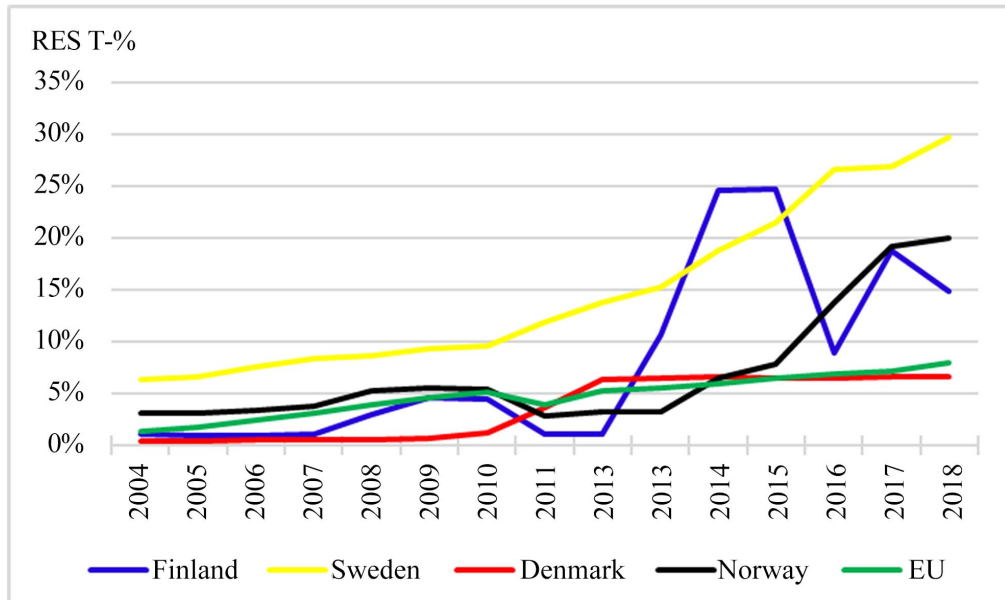

Figure 9. Share of energy from renewable sources in transport (RES-T) (2004-2018) (Eurostat).

\section{Conclusions}

A total of 53.1 Mtoe of renewable energy was used in the Nordic countries, almost half of which was bioenergy, 25.9 Mtoe in 2018. All Nordic countries have already exceeded the 2020 target for renewable energy. The Nordic countries have extensive renewable energy resources such as hydro and bioenergy, compared to the rest of Europe. Finland and Denmark are leading countries in the use of bioenergy, where the share of bioenergy in renewables was high $(79 \%$ and 64\%) followed by Sweden (55\%) and Norway (9\%) in 2018. In terms of climate, geography and industry, Finland and Sweden share many comparable characteristics. Both countries have extensive and partially untapped biomass forestry resources and a long history of forest management activities. Increased use of biomass for energy is possible because of higher harvesting volumes of roundwood from forests. The user side, which is particularly represented by the district heating industry, can be characterised as professionally managed with regard to the supply and use of forest chips. The current rate of forest fuel use can be doubled in Sweden and one and half-fold in Finland, whereas Denmark relies on imported biomass. Norway has a lot of biomass potential but low demand for forest chips. However, due to the situation in Finland and Sweden, biomass is mainly sourced domestically, since only $8 \%$ of biomass, including waste, was imported in the Nordic countries in 2013 [23]. Especially municipal and industrial wastes were traded between Sweden and Norway, which is explained by the large expansion of waste incineration plants within the Swedish district heating systems. Table 5 summarizes the success factors discussed before for the use of bioenergy in the Nordic countries. Infrastructure comprises energy use capacity and transfer network in different end-use sectors such as boilers and district heating pipeline system and transport vehicles and biofuel feeding system. Table 6 summarizes how bioenergy contributes to different end-use sectors in the Nordic countries. 
Table 5. Success factors for the use of bioenergy in the Nordic countries $(++=$ high contribution, $+=$ medium contribution, $-=$ low contribution).

\begin{tabular}{cccc}
\hline & Biomass resources & Infrastructure & Incentives \\
\hline Finland & ++ & ++ & ++ \\
Sweden & ++ & ++ & ++ \\
Norway & + & - & - \\
Denmark & - & ++ & + \\
\hline
\end{tabular}

Table 6. Contribution of bioenergy to different end-use sectors in the Nordic countries ( $++=$ high contribution, $+=$ medium contribution, $-=$ low contribution).

\begin{tabular}{cccc}
\hline & Heating/Cooling & Electricity & Transportation \\
\hline Finland & ++ & ++ & ++ \\
Sweden & ++ & + & ++ \\
Norway & + & - & - \\
Denmark & ++ & ++ & + \\
\hline
\end{tabular}

The Nordic countries accounted for $19 \%$ of the total use of bioenergy in the EU-28, 134.8 Mtoe. At the EU level the share of RES was 18.0\%, of which bioenergy made up $56 \%$ in 2018 . Bioenergy will remain by far the most important source of renewable energy in the EU as well as in Finland, Denmark and Sweden over the next decade after 2020, as it contributes both to heating and power production (CHP) and as a fuel in the transportation sector. At EU level, the bioenergy will play a major role, since the use of biomass for energy can be tripled from the present level based on reserves that have different economic and environmental constraints. The most important role in growth will be agricultural biomass in contrast to the Nordic countries, where forest biomass is the most abundant source of growth, but the growth potential is lower due to high current use [1].

\section{Conflicts of Interest}

The authors declare no conflicts of interest regarding the publication of this paper.

\section{References}

[1] Calderón, C., Ed. (2020) Statistical Report. Bioenergy Europe. https://bioenergyeurope.org/statistical-report-2019

[2] Koponen, K., Sokka, L., Salminen, O., Sievänen, R., Pingoud, K., Ilvesniemi, H., et al. (2015) Sustainability of Forest Energy in Northern Europe. VTT Technology 237. https://www.vtt.fi/inf/pdf/technology/2015/T237.pdf

[3] Zappa, W., Junginger, M. and van den Broek, M. (2019) Is a 100\% Renewable European Power System Feasible by 2050? Applied Energy, 233-234, 1027-1050. https://doi.org/10.1016/j.apenergy.2018.08.109

[4] Hansen, K., Breyer, C. and Lund, H. (2019) Status and Perspectives on 100\% Re- 
newable Energy Systems. Energy, 175, 471-480. https://doi.org/10.1016/j.energy.2019.03.092

[5] Child, M., Kemfert, C., Bogdanov, D. and Breyer, C. (2019) Flexible Electricity Generation, Grid Exchange and Storage for the Transition to a $100 \%$ Renewable Energy System in Europe. Renewable Energy, 139, 80-101.

https://doi.org/10.1016/j.renene.2019.02.077

[6] European Commission (2014) Commission Staff Working Document: State of Play on the Sustainability of Solid and Gaseous Biomass Used for Electricity, Heating and Cooling in the EU.

https://ec.europa.eu/energy/sites/ener/files/2014 biomass state of play .pdf

[7] Ericsson, K., Huttunen, S. Nilsson, L.J. and Svenningsson, P. (2004) Bioenergy Policy and Market Development in Finland and Sweden. Energy Policy, 32, 1707-1721. https://doi.org/10.1016/S0301-4215(03)00161-7

[8] Forest Europe (2015) State of Europe's Forests 2015 Report. FAO, EFI. https://foresteurope.org/state-europes-forests-2015-report/

[9] Ministry of Employment and the Economy (2010) Finland's National Action Plan for Promoting Energy from Renewable Sources Pursuant to Directive 2009/28/EC. https://www.buildup.eu/sites/default/files/content/resubmitted nreap finland en.p df

[10] Regeringsknsliet (2010) The Swedish National Action Plan for the Promotion of the Use of Renewable Energy in Accordance with Directive 2009/28/EC and the Commission Decision of 30.06.2009.

https://www.buildup.eu/sites/default/files/content/national renewable energy acti on plan sweden en.pdf

[11] Ministry of Petroleum and Energy (2012) National Renewable Energy Action Plan under Directive 2009/28/EC, Norway.

https://ec.europa.eu/energy/sites/ener/files/documents/dir 20090028 action plan norway nreap.pdf

[12] Klima-OG Energiministeriet (2010) National Action Plan For Renewable Energy in Denmark.

https://www.buildup.eu/sites/default/files/content/national renewable energy acti on plan denmark en.pdf

[13] Ministry of Employment and the Economy (2018) Finland's Fourth Progress Report under Article 22 of Directive 2009/28/EC.

https://ec.europa.eu/energy/en/topics/renewable-energy/progress-reports

[14] Regeringsknsliet (2018) Sweden's Fourth Progress Report on the Development of Renewable Energy Pursuant to Article 22 of Directive 2009/28/EC.

https://ec.europa.eu/energy/en/topics/renewable-energy/progress-reports

[15] Progress Report Norway-Template for Member State Progress Reports under Directive 2009/28/EC. (2018)

https://ec.europa.eu/energy/en/topics/renewable-energy/progress-reports

[16] Danish Report under Directive 2009/28/EC Concerning Progress in the Use and Promotion of Energy from Renewable Sources. (2018)

https://ec.europa.eu/energy/en/topics/renewable-energy/progress-reports

[17] Karhunen, A., et al. (2014) Market of Biomass Fuels in Finland-An Overview 2013. IEA Bioenergy Task 40-Country Report of Finland 2014. http://task40.ieabioenergy.com/iea-publications/country-reports/

[18] Hector, B., et al. (2014) Country Report Sweden. IEA Bioenergy Task 40. http://task40.ieabioenergy.com/iea-publications/country-reports/ 
[19] Trømborg, E. (2015) IEA Bioenergy Task 40-Country Report 2013 for Norway. http://task40.ieabioenergy.com/iea-publications/country-reports/

[20] Stelte, W., et al. (2015) Country Report 2014 for Denmark. IEA Bioenergy Task 40. http://task40.ieabioenergy.com/iea-publications/country-reports/

[21] Natural Resources Institute Finland (2020) Wood in Energy Generation 2019 (Provisional). https://stat.luke.fi/en/wood-energy-generation-2019-provisional en

[22] Council of European Energy Regulators (2017) Status Review of Renewable Support Schemes in Europe. https://www.ceer.eu/documents/104400/-/-/41df1bfe-d740-1835-9630-4e4cccaf8173

[23] Bostedt, G., Mustonen, M. and Gong, P. (2016) Increasing Forest Biomass Supply in Northern Europe-Countrywide Estimates and Economic Perspectives. Scandinavian Journal of Forest Research, 31, 314-322. https://doi.org/10.1080/02827581.2015.1089930

[24] Natural Resources Institute Finland, Statistics Finland (2020) Total Roundwood Removals and Drain by Region, 2018.

http://stat.luke.fi/en/roundwood-removals-and-drain

[25] Forest Statistics 2020 (2020) Official Statistics of Sweden. Swedish University of Agricultural Sciences. Umeå.

https://www.slu.se/globalassets/ew/org/centrb/rt/dokument/skogsdata/skogsdata 2 $\underline{020 \text { webb.pdf }}$

[26] Ranta, T., Karhunen, A. and Laihanen, M. (2017) Factors behind the Development of Forest Chips Use and Pricing in Finland. Biomass and Bioenergy, 98, 243-251. https://doi.org/10.1016/j.biombioe.2017.02.004

[27] IEA (2016) Nordic Energy Technology Perspectives 2016. Norden. https://www.nordicenergy.org/wp-content/uploads/2016/04/Nordic-Energy-Techn ology-Perspectives-2016.pdf

[28] Huttunen, R., Ed. (2017) Government Report on the National Energy and Climate Strategy for 2030. Publications of the Ministry of Economic Affairs and Employment. http://urn.fi/URN:ISBN:978-952-327-199-9

[29] IEA (2018) Energy Policies of IEA Countries. Finland. 2018 Review. https://webstore.iea.org/energy-policies-of-iea-countries-finland-2018-review

[30] Hakkarainen, E., Hannula, I. and Vakkilainen, E. (2019) Bioenergy RES Hybrids-Assessment of Status in Finland, Austria, Germany, and Denmark. Biofuels, Bioproducts and Biorefining, 13, 1402-1416. https://doi.org/10.1002/bbb.2019

[31] Directive 2009/28/EC of the European Parliament and of the Council of 23 April 2009 on the Promotion of The Use of Energy from Renewable Sources and Amending and Subsequently Repealing Directives 2001/77/EC and 2003/30/EC. http://data.europa.eu/eli/dir/2009/28/oj 